\title{
Peripartum Cardiomyopathy: Epidemiological, Clinical, Para-Clinical and Therapeutic Aspects at the Tombouctou Hospital
}

\author{
Souleymane Mariko1*, Massama Konaté2, Samba Sidibé ${ }^{3}$, Karamoko Kantako1, Charles Dara1, \\ Djibril Kassogué ${ }^{4}$, Nouhoum Diallo ${ }^{3}$, Coumba A. Thiam ${ }^{5}$, Aniessa Kodio ${ }^{6}$, Mariam Sako ${ }^{3}$, \\ Abdoul Karim Sacko33, Mamadou Diakité3 ${ }^{3}$, Souleymane Coulibaly33, Ilo Bella Diall33, \\ Ichaka Menta7
}

\author{
${ }^{1}$ General Medicine Service, Tombouctou Hospital, Tombouctou, Mali \\ ${ }^{2}$ Cardiology Department, Mali Hospital, Bamako, Mali \\ ${ }^{3}$ Cardiology Department Point G Hospital University Center, Bamako, Mali \\ ${ }^{4}$ Department of Pediatrics, Tombouctou Hospital, Tombouctou, Mali \\ ${ }^{5}$ Cardiology Department Kati Hospital University Center, Kati, Mali \\ ${ }^{6}$ Cardiology Department, Ségou Hospital, Ségou, Mali \\ ${ }^{7}$ Cardiology Department Gabriel Touré Hospital University Center, Bamako, Mali \\ Email: *souuleymanemariko@yahoo.fr
}

How to cite this paper: Mariko, S., Konaté, M., Sidibé, S., Kantako, K., Dara, C., Kassogué, D., Diallo, N., Thiam, C.A., Kodio, A., Sako, M., Sacko, A.K., Diakité, M., Coulibaly, S., Diall, I.B. and Menta, I. (2021) Peripartum Cardiomyopathy: Epidemiological, Clinical, Para-Clinical and Therapeutic Aspects at the Tombouctou Hospital. World Journal of Cardiovascular Diseases, 11, 167180

https://doi.org/10.4236/wjcd.2021.113018

Received: February 2, 2021

Accepted: March 20, 2021

Published: March 23, 2021

Copyright $\odot 2021$ by author(s) and Scientific Research Publishing Inc. This work is licensed under the Creative Commons Attribution International License (CC BY 4.0).

http://creativecommons.org/licenses/by/4.0/

\section{Open Access}

\begin{abstract}
Introduction: Peripartum cardiomyopathy (PPCM) is a heart failure whose etiology is still unknown. The aim of work was to study peripartum cardiomyopathy in its epidemiological, clinical, paraclinical and therapeutic aspects at the Tombouctou hospital. Methods: This is a descriptive cross-sectional study carried out in the Medicine Department of the Timbuktu hospital from January 1 to December 31, 2019. It concerned patients who presented heart failure between the 8th month of pregnancy and the first 5 months postpartum. Results: During the study, 23 patients were collected. Average age of the patients was $23.50 \pm 3.50$ years with extremes of 16 and 34 years. Incidence of Peripartum cardiomyopathy (PPCM) was $1 / 345$ pregnancies. Average parity was 3.20 with extremes of 1 and 8 . Symptoms appeared at postpartum with $87 \%$ of cases. A significant delay in diagnosis was observed. Global heart failure was the mode of decompensation with $70 \%$. Electrocardiographic signs were mainly sinus tachycardia (87\%) and left ventricular hypertrophy (83\%). Cardiac ultrasound showed in all cases dilated cardiomyopathy and it was associated with thrombus in left ventricle cavity for three cases. Left ventricular ejection fraction was severely impaired in $70 \%$ of cases. Pulmonary hypertension was significant in 52\%. Most commonly drugs we used in our series at acute stage were duretics: furosemide $100 \%$ and spironolactone $70 \%(100 \%$
\end{abstract}


and 70\%) and ACE inhibitors (90\%). Beta-blockers (bisoprolol and carvedilol) were used in 15 patients. Bromocriptine (prolactin inhibitor) was used for 2 patients. Conclusion: Peri partum cardiomyopathy is a serious cardiac complication of pregnancy of unknown cause, common in the African population.

\section{Keywords}

Heart Failure, Cardiomyopathy, Peripartum, Treatment

\section{Introduction}

Peripartum cardiomyopathy (PPCM) or Meadows syndrome is an apparently primary heart failure with a dilated heart occurring between the eightieth month of pregnancy and the first five months after childbirth in women with previously healthy hearts [1] [2]. It is a pathology whose etiology remains unknown today, hence its name of idiopathic or primary cardiomyopathy [3] [4]. Globally, this disease is more common in Sub-Saharan-Africa than in other regions. It accounts for less than $1 \%$ of cardiovascular problems associated with pregnancy in developed countries and overall incidence is estimated at in 3 to 4000 births with a wide geographical variety [5]; but it would be more frequent in black women and particularly in black Africa [6] [7]. A study from Togo showed incidence of Peripartum cardiomyopathy (PPCM) was $1 / 362$ pregnancies [8]. According to a study carried out at the Gabriel Touré University Hospital from Mali Peripartum cardiomyopathy represented $6.8 \%$ of hospitalizations in the cardiology department and $11.4 \%$ of hospitalizations for heart failure in women [9].

\section{Aim of the Study}

To study the cardiomyopathy of the peripartum in its epidemiological, paraclinical and therapeutic aspects at the Timbuktu hospital.

\section{Patients and Methods}

This is a descriptive cross-sectional study that took place over a 12-month period from January 1 to December 31, 2019 in the Medicine Department of Tombouctou Hospital.

Were included in the study women who presented with heart failure (HF) between the eightieth month of pregnancy and the first five months postpartum without a found etiology and in whom dilated cardiomyopathy (DCM) was diagnosed at the cardiac ultrasound doppler. Women with onset of heart failure before the eightieth month of pregnancy or after the first six months postpartum, women with known heart disease or any other cause of heart failure were not included in the study. In addition to the absence of a cause of heart failure, the following ultrasound criteria were essential to retain the diagnosis of peri- 
partum cardiomyopathy: dilation of the left ventricle (telediastolic diameter of the left ventricle $>32 \mathrm{~mm} / \mathrm{m}^{2}$ of body surface area) with left ventricular systolic dysfunction i.e. lower left ventricular ejection fraction (LVEF) under 0.45 and/or shortening fraction $<30 \%$.

\subsection{Operational Definition}

Heart failure is a complex clinical syndrome. It is the inability of the heart (right and/or left) to maintain sufficient flow at rest and exertion to meet the metabolic needs of the body; or the heart can only do so at the cost of increased ventricular filling pressures

Criteria for defining socioeconomic level:

- Low: laborers, low-income farmers, retail traders and casual workers (Low income).

- Middle: middle state executives (high school teachers, senior health technicians, etc.) and/or from the private sector and middle traders (average income).

- High: senior officials of the State and/or the private sector and import-export traders (High income).

\subsection{Collection of Data}

A pre-established survey sheet was used to collect demographic data, data from antenatal consultations, cardiovascular risk factors, the mode of occurrence or decompensation of HF, the mode and course of childbirth. Chronology of signs of HF in relation to childbirth, and data from the physical and paraclinical examination.

Paraclinical data were obtained from the following examinations: chest $\mathrm{x}$-ray, electrocardiogram, cardiac echodoppler, biology (complete blood count, glycemia, creatinemia, uricemia, proteinuria, ionogram blood, HIV serology).

\subsection{Data Entry and Analysis}

Word and Excel 2013 software were used for data entry and SPSS11 and Epi Info 3.3.2 software for their analysis. The statistical test used was Ki2 with a significance level of $5 \%$.

\subsection{Ethics}

Informed consent was obtained with strict respect for confidentiality.

\section{Results}

\subsection{Epidemiological Aspects}

We recorded 23 cases of peripartum cardiomyopathy with an incidence of 1/345 pregnancies. Average age was $23.50 \pm 3.50$ years (range from 16 and 34). Women aged between 20 - 29 years were $52 \% ; 22 \%$ of cases were at least 30 years old and $26 \%$ of patients were under 20 years old. Peripartum cardiomyopathy ac- 
counted for $3.36 \%$ of hospitalizations in the medical department, $18 \%$ of heart failure and $33 \%$ of heart failure in women. Unemployed women represented $78 \%$ of the sample. Women were of unfavorable socio-economic conditions in $91 \%$. Multiparas were the most represented in our series with $61 \%$. Average parity was 3.45 (range from 1 to 8 ). Table 1 summarizes data of the socio-demographic characteristics.

\subsection{Clinical Aspects}

In $87 \%$ of cases symptoms appeared in the postpartum period (Figure 1). A delay in consultation was noted in all patients with an average delay of 43 days (range from: 5 to 105 days). Symptoms were dominated by dyspnea on exertion (Table 2). Decompensation was done in the mode of isolated left heart failure in $30 \%$ of cases and in the mode of global heart failure in $70 \%$ of cases. Table 3 summarize data from the physical examination.

Table 1. Socio-demographic characteristics.

\begin{tabular}{ccc}
\hline Age & Effective & Frequency (\%) \\
\hline Under 20 & 12 & 26 \\
$20-29$ years & 6 & 52 \\
30 ans and over & 5 & 22 \\
Total & 23 & 100 \\
Parity & & \\
4 à 8 & 14 & 61 \\
$2-3$ & 6 & 26 \\
1 & 3 & 13 \\
Total & 23 & 100,0 \\
Socioeconomic level & & 91 \\
Low & 21 & 9 \\
Middle & 2 & 0 \\
High & 0 & 100 \\
Total & 23 & \\
\hline & & 9
\end{tabular}

Table 2. Functional signs.

\begin{tabular}{ccc}
\hline & Number & Percent\% \\
\hline Dyspnea NYHA stage IV & 14 & 61 \\
Dyspnea NYA stage III & 9 & 39 \\
Cough & 17 & 74 \\
Oedema of the lower limbs & 16 & 69 \\
Palpitations & 8 & 35 \\
Precordial pain & 5 & 22
\end{tabular}


Table 3. Min anomalies of physical examination.

\begin{tabular}{ccc}
\hline & Number & Percent\% \\
\hline Tachycardia & 20 & 87 \\
Galopping noise & 19 & 83 \\
jugular turgescence & 16 & 69 \\
Systolic murmur & 15 & 65 \\
Hepatomegaly & 13 & 56 \\
Hepato-jugular reflux & 15 & 65 \\
\hline
\end{tabular}

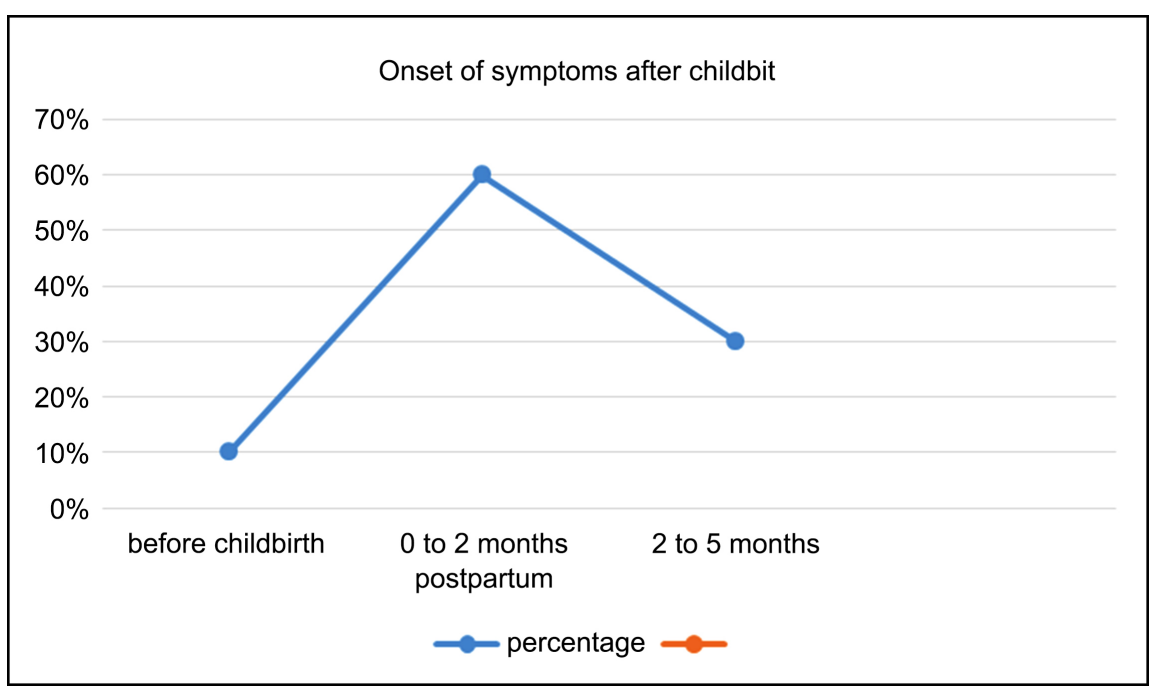

Figure 1. Onset of symptoms after childbirth.

\subsection{Paraclinical Aspects}

The frontal chest X-ray: had objectified cardiomegaly in 20 patients (87\%) with an average cardio-thoracic index of 0.58 (extreme 0.55 to 0.78 ).

Electrocardiogram: found sinus tachycardia in $87 \%$ of cases, left ventricular hypertrophy in 19 patients (83\%). Fifteen patients (65\%) had left atrial hypertrophy and $26 \%$ of patients had bi-ventricular hypertrophy. There were no atrioventricular conduction disturbances. We noted a case of complete left bundle branch block with QRS at $160 \mathrm{~ms}$. In 13 cases (56\%), nonspecific repolarization disorders were noted associated with ventricular hypertrophies. The electrocardiogram was normal in 2 cases.

\subsection{Transthoracic Echocardiographic Data}

Left ventricle was dilated in all patients with a tele diastolic diameter ranging from 33.6 to $43 \mathrm{~mm} / \mathrm{m}^{2}$ body surface area ( 57.8 to $80 \mathrm{~mm}$ ). Left atrium was dilated in 19 patients (83\%), Right ventricle was dilated in 15 patients (65\%). Average Left ventricle ejection fraction (EF) was 0.30 (range 0.18 and 0.40 ). Ejection fraction was severely impaired in $69 \%$ of cases. Systolic myocardial wave (Sa) was lowered in all patients with a mean of 0.39 (range 0.20 and 0.65 ). All 
patients presented with global parietal hypokinesia. Cardiac Doppler ultrasound revealed a thrombus in left ventricle cavity for 3 patients (13\%). Functional mitral insufficiency was found in $69 \%$. Left ventricular filling pressures were increased for 18 patients (78\%). Pulmonary arterial hypertension was significant in $52 \%$ of cases with an average of $43.40 \mathrm{mmHg}$ (range from: 37 and $70 \mathrm{mmHg}$ ).

\subsection{Therapeutic Aspects}

Most drugs used in patients for our at acute stage were duretics: furosemide and spironolactone diuretics (furosemide100\% and spironolactone 69\%) and ACE inhibitors (90\%). Beta-blockers (bisoprolol and carvedilol), were used for $15 \mathrm{pa}$ tients. Bromocriptine (prolactin inhibitor) was used for 2 patients. Low molecular weight heparin (LMWH) curative dose anticoagulation was performed during hospitalization in $3(13 \%)$ patients with intracavitary thrombus. All these patients benefited from a relay with Vitamin K antagonist (VKA). Moreover, all of our patients received heparinotherapy at a preventive dose or a curative dose during hospitalization.

Family planning was discussed with 18 patients before discharge from hospital. It was only effective with 7 patients ( 6 patients benefited from an mechanical method and one from subcutaneous method norplant).

Average length of stay at hospital for our patients was 7 days (range from 4 to 20 days). Twenty-one patients (91\%) had recovered clinically with disappearance of the signs, two patients (9\%) had developed irreducible heart failure. The hospital case fatality rate was zero.

\section{Discussion}

\subsection{Our Study Suffered from Certain Limitations, Particulary}

- Financial difficulty for patients to do initial cosultation and security difficulty for patients who came from outside the city Tombouctou to do initial consultation,

- Small sample size.

\subsection{Epidemiological and Clinical Aspects}

Incidence of peripartum cardiomyopathy was $1 / 345$ pregnancies in our study. In Africa the incidence of peripartum cardiomyopathy is variable [4] [6] [8] [9]. In West Africa disease seems less frequent with an incidence from $1 / 3000$ to $1 / 15,000$ [7]. These results confirm that peripartum cardiomyopathy is a pathology that is most prevalent in black women [10] [11]. Other associated factors are advanced maternal age [12]. In this study, Average parity was 3.45 (range from: 1 and 8) with $61 \%$ multiparas. This testifies to the frequency of this affection in multiparous women [12]. In addition, $91 \%$ of the patients were from low socio-economic conditions. We share with authors that low socioeconomic level is also a risk factor for peripartum cardiomyopathy [13]. 
Multiparity and unfavorable socio-economic conditions are risk factors for peripartum cardiomyopathy founded in this study. Other factors such as notion of chronic arterial hypertension and prolonged use of tocolytics, twin pregnancies [12] cannot be formally retained in this study.

We observed a great delay in consultation among our patients. Dyspnea on exertion was the master symptom with an advanced stage of NYHA classification. Same findings were reported in African literature [4] [6] [8] [9] [13]. These are actually patients in whom the symptoms start earlier but ignorance and poverty are the causes of consultation delays and most of the patients are found in a stage of global heart failure with a state of hydrops. Women considered edema of the limbs as a normal fact related to pregnancy and when they had dyspnea with increase of intensity majority of patients done consultation. Other symptoms founded were precordial pain and cough. Precordial pains ranged from a simple precordial tingling to angina-like pain with a feeling of chest tightness. Their frequency varies according to the authors [6] [8] [9] [11] [13]. These chest pains associated with coughing pose a real diagnostic problem because they can raise suspicion of pulmonary embolism. Due to the limited diagnostic resources, five of our patients were put on an anticoagulant at a curative dose due to a strong suspicion of pulmonary embolism and the rest of the patients were on the preventive dose during hospitalization. Tachycardia with galloping noise, systolic murmur of mitral insufficiency and crackling rales were the most frequent auscultatory data found in our patients. Several authors have reported the same data from physical examination but at widely varying rates [4] [6] [8] [9] [13]. Statistical disparities are explained by the subjective nature of the clinical examinations, hence the need for paraclinical examinations.

\subsection{Paraclinical Aspects}

Cardiomegaly was noted at chest X-ray in $87 \%$ of cases in this study. Cardiomegaly is constant in heart failure but remains nonspecific [14]. Chest X-ray is essential in our regions where cardiac ultrasound doesn't exist in medical care centers.

On electrocardiogram, arrhythmias are reported in the literature. Ferrière [15] on 11 observations noted 1 case of ventricular tachycardia. This is a ventricular tachycardia detected by holter ECG recording. Sinus tachycardia, left ventricular hypertrophy and nonspecific repolarization disorders are the electrical abnormalities frequently found [6] [8] [9] [13]. In our series we objectified a complete left bundle branch block.

In from a recent childbirth woman who complains of dyspnea, discovery of cardiomegaly at Chest X-ray associated with sinus tachycardia and left ventricular hypertrophy at EKG should lead to peripartum cardiomyopathy until proven otherwise. Cardiac Doppler ultrasound will only come to confirm diagnosis and appreciate impact and complications of disease.

Echocardiographic signs are one of the defining criteria for peripartum car- 
diomyopathy and global parietal hypokinesia is the constant disorder found [2] [15]. Cavity dilation as well as systolic left ventricular dysfunction were severe in our patients. These are the consequences of delayed consultation and diagnosis. Peripartum cardiomyopathy is a highly embologenic pathology [8] [10]. Reasons are multiple: hypercoagulability of the blood during pregnancy [16], dilated cardiomyopathy which appears in a recent childbirth woman, reduced maternal mobility during the last months of pregnancy, compression of the inferior vena cava by the fetus.

\subsection{Therapeutic and Evolutionary Aspects}

Treatment in acute stage is dominated by diuretics (furosemide and spironolactone). ACE inhibitors were the second most widely used drugs in our study. This therapeutic attitude is found in several studies [20] [21]. In our series beta blockers were used after acute stage of disease which is consistent with the data in the literature [5]. On the other hand, bromocriptine, a prolactin inhibitor which has been shown to be effective in a randomized controlled trial [22], is little used in our series.

Evolution of peripartum cardiomyopathy is unpredictable [17]. Inter-reproductive interval depends on the time it takes for systolic function to recover normal function. When heart failure persists beyond sixtieth month after childbirth, mortality at one year is $28 \%$ in one year and at 5 years is $85 \%$ [2] [3]. Resistant forms to medical treatment in the literature represent $10 \%$ of cases [17] in our series, two patients (9\%) presented with this form. When peri partum cardiomyopathy is healed, risk of recurrence in a subsequent pregnancy cannot be excluded. Advice for patients is therefore adapted to each case. Some characteristic are considered to have a poor prognosis. These are of African origin, age greater than 30 , a delay in onset of symptoms greater than 3 months, persistence of clinical signs 6 months after the onset of the disease, cardio-thoracic index at chestx-ray greater than 0.6 and the characteristics of the left ventricle at transthoracic echocardiography like: dilation (end diastolic diameter of the left ventricle $<55-60 \mathrm{~mm}$ ), an ejection fraction $<30 \%$, a shortening fraction less than $20 \%$ at the time of diagnosis [2] [16]. If we consider these factors, we will say that all of our patients had a poor prognosis.

Prognosis of the disease is unpredictable.In the literature many patients die despite treatment, while others progress quite favorably, and after 6 to 12 months of treatment, complete recovery is observed [2] [16]. Between healing and death, the course is from chronic heart failure to dilated cardiomyopathy [18]. The obstetric prognosis is poor. Heart failure occurs in $50 \%-80 \%$ of cases in subsequent pregnancies, with mortality reaching $60 \%$ [19]. Given a very high mortality during subsequent pregnancies, we agreed with our multiparous patients to opt for a contraindication for permanent pregnancy. First-time mothers wishing to have another pregnancy are followed up and decisions, that is to say the normalization of cardiac function. 


\section{Conclusion}

Peripartum cardiomyopathy is a serious cardiac complication of pregnancy. It is common in Timbuktu as in other black African countries. It occurs preferentially in the postpartum period. Risk factors were: maternal age over 30 years, multiparity and unfavorable socio-economic conditions. There was a significant delay in diagnosis. Clinical picture was global heart failure with significant dilation of $t$ heart chambers and severe impairment of myocardial performance.

\section{Acknowledgements}

We thank the management of the Tombouctou Hospital for completing the administrative and regulatory formalities for this work, as well as the patients for their trust.

\section{Conflicts of Interest}

The authors declare no conflicts of interest regarding the publication of this paper.

\section{References}

[1] Demakis, J.G., Rahimtoola, S.H., Sutton, G.C., et al. (1971) Natural Course of Peripartum Cardiomyopathy. Circulation, 44, 1053-1056.

https://doi.org/10.1161/01.CIR.44.6.1053

[2] Hibbard, J.U., Lindheimer, M. and Lang, R. (1999) A Modified Definition for Peripartum Cardiomyopathy and Prognosis Based on Echocardiography. Obstetrics \& Gynecology, 94, 311-316. https://doi.org/10.1097/00006250-199908000-00030

[3] Sliwa, K., Hilfiker-Kleiner, D., Petrie, M.C., et al. (2010) Current State of Knowledge on Aetiology, Diagnosis, Management, and Therapy of Peripartum Cardiomyopathy: A Position Statement from the Heart Failure Association of European Society of Cardiology Working Group on Peripartum Cardiomypathy. European Journal of Heart Failure, 12, 767-778. https://doi.org/10.1093/eurjhf/hfq120

[4] Ntusi, N. and Mayosi, B.M. (2009) Aetiology and Risk Factors of Péripartum Cardiomyopathy: A Systematic Review. International Journal of Cardiology, 131, 168 179. https://doi.org/10.1016/j.ijcard.2008.06.054

[5] Dembélé, A. (2020) Peripartum Cardiomyopathy in the Cardiology Department of the Point G University Hospital in Bamako, Medecine Thesis, Bamako, No. 117.

[6] Niakara, A., Belemwire, S., Nebie, L. and Drabo, Y. (2000) Post-Partal Cardiomyopathy in Black African Women: Epidemiological, Clinical and Evolutionary Aspects of 32 Cases. Cardiologie Tropicale, 26, 69-73.

[7] Mielniczuk, L.M., Williams, L., Davis, D.R., et al. (2006) Frequency of Péripartum Cardiomyopathy. The American Journal of Cardiology, 97, 1765-1768. https://doi.org/10.1016/j.amjcard.2006.01.039

[8] Pio, M., Afassinou, Y., Baragou, S., et al. (2014) Special Features of Peripartum Cardiomyopathy in Africa: The Case of Togo on a Prospective Study of 41 Cases at Sylvanus Olympio University Hospital of Lome. The Pan African Medical Journal, 17, 245.

[9] Ment, I., Ba, H.O., Coulibaly, S., Bagayogo, D., et al. (2018) The Peri-Partum Cardiomyopathy in the Cardiology Department of ChuGabriel Touré of Bamako. Car- 
diology \& Vascular Research, 2, 1-4. https://doi.org/10.33425/2639-8486.1015

[10] Brar, S.S., Khan, S.S., Sandhu, G.K., Jorgensen, M.B., Parikh, N., Hsu, J.W. and Shen, A.Y. (2007) Incidence, Mortality, and Racial Differences in Peripartum Cardiomyopathy. The American Journal of Cardiology, 100, 302-304.

https://doi.org/10.1016/j.amjcard.2007.02.092

[11] Gentry, M.B., Dias, J.K., Luis, A., Patel, R., Thornton, J. and Reed, G.L. (2010) African-American Women Have a Higher Risk for Developing Peripartum Cardiomyopathy. Journal of the American College of Cardiology, 55, 654-659.

https://doi.org/10.1016/j.jacc.2009.09.043

[12] Heider, A.L., Kuller, J.A., Strauss, R.A. and Wells, S.R. (1999) Peripartum Cardiomyopathy: A Review of the Literature. Obstetrical and Gynecological Survey, 54, 526-531. https://doi.org/10.1097/00006254-199908000-00023

[13] Katibi, I. (2003) Peripartum Cardiomyopathy in Nigeria. Hospital Medecine (London, England), 64, 249.

[14] Moioli, M., Valenzano Menada, M., Bentivoglio, G. and Ferrero, S. (2010) Peripartum Cardiomyopathy. Archives of Gynecology and Obstetrics, 281, 183-188. https://doi.org/10.1007/s00404-009-1170-5

[15] Ferriere, M., Sacrez, A., Bouhour, J.B., et al. (1990) Peripartum Cardiomyopathy: Current Aspects. Multicenter Study: 11 Observations. Archives des Maladies du Coeur et des Vaisseaux, 83, 1563-1569.

[16] Walkira, S., Carnério de Carvalho, M., Cleide, K. and Rossi, E. (2002) Pregnancy and Peripartum Cardiomyopathy: A Comparative and Prospective Study. Arquivos Brasileiros de Cardiologia, 79, 489-493. https://doi.org/10.1590/S0066-782X2002001400006

[17] Burban, M. (2002) Pregnancy and Dilated or Hypertrophic Cardiomyopathies. Archives des Maladies du Coeur et des Vaisseaux, 95, 287-291.

[18] Rifat, K. (1995) La cardiomyopahie du peripartum (CMPP). Medecine and Hygiene, 53, 2548-2550.

[19] Hamdoum, L., Mouelhi, C., Kouka, H., et al. (1993) Peripartum Cardiomyopathy. Analysis of Three Cases and Review of the Literature. French Journal of Gynecology and Obstetrics, 88, 273-275.

[20] Adjagba, P.M., Vlanovou, M.I.D., Codjo, L., Sonou, A., Hounkponou AmoussouGuenou, M., Bognon, R., et al. (2017) Peripartum Cardiomypathy at the Cardiology Department of CNHU-HKM, Cotonou, Benin. Tropical Cardiology, 149.

[21] Mongo Ngamami, S.F., Ellenga Mbolla, B.F., Nzaka-Sikou, S., Kouala-Landa, C., et al. (2014) Peri-Partum Cardiomyopathy: Epidemiological, Clinical and Prognostic Aspects in the Cardiology and Internal Medicine Department of the Brazzaville CHU (Congo). African and Malagasy Journal of Scientific Reearch and Health Sciences, 2, 69-73.

[22] Sliwa, K., Blauwet, L., Tibazarwa, K., et al. (2010) Evaluation of Bromocriptine in the Treatment of Acute Severe Peripartum Cardiomyopathy: A Proof-of-Concept Pilot Study. Circulation, 121, 1465-1473.

https://doi.org/10.1161/CIRCULATIONAHA.109.901496 


\section{Survey Sheet}

NumberSurvey Sheet:

\section{Socio-Demographics Data}

Last Name:

First Name.

Age.

Profession.

Socioeconomic level $\neq$ : low / / middle / / High / / $\neq$ Criteria for defining socioeconomic level:

- Low: laborers, low-income farmers, retail traders and casual workers (Low income).

- Middle: middle state executives (high school teachers, senior health technicians, etc.) and/or from the private sector and middle traders (average income).

- High: senior officials of the State and/or the private sector and import-export traders (High income).

\section{Past Medical History}

1) Personal history

a) Medical

- Hypertension:

yes / / no / /

- Diabetes:

yes / / no / /

- Heart failure: yes / /

no / /

- Asthma:

yes / /

No / /

- Drepanocyt:

yes / / Non / /

- Dysthyroidism:

yes / / No/ /

- Other (s) to be specified:

b) Obstetric history Number of pregnancies:

- Twin pregancy: yes / / Number:

- Prenata consultation: yes / / No / /

- Other (s) to be specified: 2) Family history

- Arterial hypertension:

- Diabetes:

$\begin{array}{ll}\text { yes / / } & \text { No / / } \\ \text { yes / / } & \text { No / / } \\ \text { yes / / } & \text { No / / }\end{array}$

- Heart failure:

- Other (s) to be specified.

\section{Socioeconomic Level}

Socioeconomic level: $\quad$ Low / / Middle / / High / /

\section{Clinical Examinations}

1) Onset of symptoms 
Peripartum: Ante-partum yes / / no / / if yes month of pregnancy [......] Post-partum yes / / no / / if yes number of days after childbirth [...]

2) Functional signs

- NYHA of dyspnea stage:

Stage I / /

- cough:

- Hemoptysis:

- Precordial pain:

- Palpitations:

3) General signs

a) General condition: Good / / Fair / / Impaired / /

b) Conjunctiva: Colored / / Few colored / / Pale / /

c) Weight: kg Size: metre

d) Blood pressure: .mm hg

4) Physical signs
a) Tachycardia:
b) Galopping noise:
yes / /
No / /
c) Deviated peak shock:
yes / / No/ /
d) crackling groans:
yes / / No/ /
e) Hepatomegaly:
yes / / No/ /
f) Jugular turgescence
g) Hepato-jugular reflux:
yes / / No/ /
yes / / No/ /
yes / / No/ /
h) Oedema of the lower limbs:
i) Murmur of MI:
yes / / No/ /
j) Murmur of TI:
yes / / No/ /
yes / / No/ /
k) Other (s) to be specified:
5) Type of the heart failure
a) Left:
b) Global:
yes / / No/ /
yes / / No/ /

\section{Additional Tests}

1) Electrocardiogram

- Sinus tachycardia:

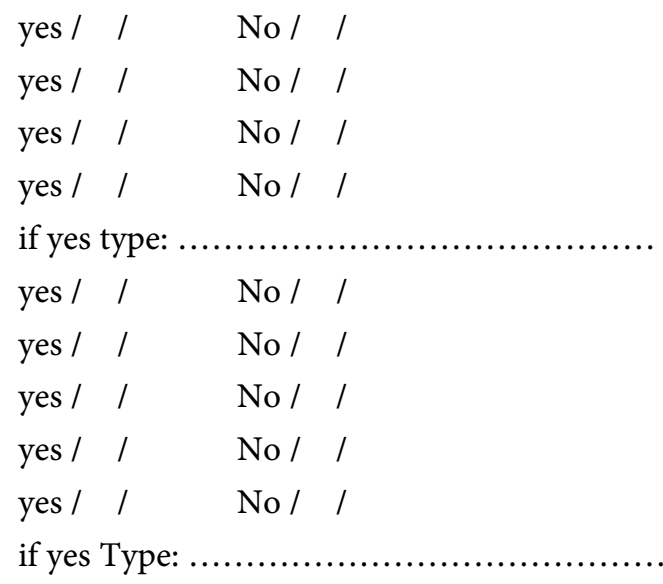


- Left bundle branch block: Yes / / No / /

- Right bundle branch block: Yes / / No / /

- QRS duration:......................................ms

- Repolarization: normale / / Anormal/ /

if abnormal: type...........and territory

2) Trans-Thoracic Echocardiography

VG diameter in $\mathrm{mm} / \mathrm{m}^{2}$ body surface area: $\mathrm{mm} / \mathrm{m}^{2}$

$\mathrm{LV}$ diastolic tele diameter in $\mathrm{mm}$ : ...mm

Anteroposterior diameter of the left atrium: ..mm

Left atrium area: .......... $\mathrm{cm}^{2}$, Left atrium volume:........ $\mathrm{ml} / \mathrm{m}^{2}$ of body surface area Diameter of the ventricle at the level of the tricuspid ring: ............mm

Right atrium area: $\mathrm{cm}^{2}$

Diameter of the septum in tele diastole: $\mathrm{mm}$

Posterior wall diameter in diastole: .........mm

Global kinetics: normal:........ Global hypokinesia........

Segmental kinetics disorder: present: Absent:

LV ejection fraction:

Transmitral flow: normal / / relaxation disorder / / Restrictive / /

Tissue Doppler: E'/A' = $\mathrm{S}$ wave velosity (basal) in $\mathrm{cm} / \mathrm{second}$ :

Appearance of the valves:

Normal mitral valve... Remodeled calcified Leak

If Yes type: Rank:

Normal Aortic Valve. Remodeled calcified Leak.

If Yes type: Rank:

Normal Tricuspid Valve.... Remodeled calcified Leak.......... If Yes type: Rank

Normal Pulmonary Valve Remodeled. calcified. Leak

If Yes type: . Rank:

PAPS: $\mathrm{mmHg}$

Pericardial effusion yes / / no / /

Presence of intracavitary thrombus: Yes / / no / /

if Yes Location

3) chest x-ray

- Cardiomegaly:

Yes / /

CTI:

No / /

- Signs of veno-capillo-pulmonary hyperpressure Yes / / No/ /

- Alveolar syndrome: Yes / / No / /

- Interstitial syndrome: Yes / / No / /

- Other (s) to be specified:

4) Blood count

- Anemia: YES / /

No / /

Hemoglobin level....

- Hyperleukocytosis:

Yes / / No/ /

- Leukopenia:

Yes / / No/ /

- Thrombocytopenia:

Yes / / No/ /


5) Biochemistry

- Blood creatinine:
Normal / /

Normal / /

Normal / /
Normal / /

- HIV serology: Negative / / Positive / / if positive type:

High / /

Low / / High / /

Abnormal / /

High / /

- Other (s) to be specified:

\section{Treatment}

- Hygienic-dietetic measure:

$\begin{array}{ll}\text { Yes / / } & \text { No / } \\ \text { Yes / / } & \text { No / } ~ \\ \text { Yes / / } & \text { No / / } \\ \text { Yes / / } & \text { No / / }\end{array}$

- Diuretics: Furosemide

\section{Spironolactone}

if yes Type

- Anti-platelet agents:

$$
\text { Yes / / }
$$

No / /

if yes Type

- Anticoagulant:

$$
\begin{aligned}
& \text { Yes / / } \\
& \text { if yes Type }
\end{aligned}
$$

No / /

- Bromocriptine:

Yes / /

No / /

- Beta blockers:

Yes / /

No / /

if yes Type

- Other (s) to be specified:....

- Complication and Evolution

Complications during hospitalization

- MVTE: TVP / / EP / /

- Cerebrovascular accident: Yes / / No / /

- Rhythm disorder: Yes / / Type........ No / /

- Chronic heart failure: Yes / / No / /

- Other (s) to be specified:...

\section{Evolution during Hospitalization}

- Favorable: Yes / / No / /

- Stationary (persistence of signs of heart failure: Yes / / No / /

- Death: Yes/ / No / / 